\title{
Cross-cultural validation of a French version of the Emotional Processing Scale (EPS-25)
}

\section{Validation française de l'Echelle des Processus Emotionnels (EPS-25)}

GAY Marie-Claire, Psychology Department, University of Paris West, Nanterre, France BAKER Roger Bournemouth University, Clinical Research Unit, Faculty of Health and Social Sciences, Bournemouth, UK

VRIGNAUD Pierre, University of Paris West, Psychology Department, Nanterre, France

THOMAS Peter, Bournemouth University, Clinical Research Unit, Faculty of Health and Social Sciences, Bournemouth, UK

HEINZLEF Olivier, Centre Hospitalier Inter-Universitaire, Poissy-St Germain-en Laye, Poissy, France.

HAAG Pascale, Psychology Department, Ecole des Hautes Etudes en Sciences Sociales (EHESS), Paris. France

BANOVIC Ingrid, Psychology Department, Université de Rouen, France

THOMAS Sarah, Bournemouth University, Clinical Research Unit, Faculty of Health and Social Sciences, Bournemouth, UK

Corresponding author: Gay Marie-Claire, University of Paris West, Psychology Department, Nanterre, France

Email : marieclaire.gay@gmail.com

Phone : +33 649274388 


\section{Cross-cultural validation of a French version of the Emotional Processing Scale (EPS-}

25)

\section{Validation française de l'Echelle des Processus Emotionnels (EPS-25)}

\section{Résumé}

Objectif: l'Echelle des Processus Emotionnels (Emotional Processing Scale -EPS) est un autoquestionnaire de 25 items utilisé pour évaluer les styles de traitement émotionnels et leurs dysfonctionnements. Notre objectif était de traduire et de valider cette échelle en français auprès d'une population tout venant et clinique.

Méthode: après une traduction et une rétrotraduction, l'étude de validation a été menée auprès de 1176 adultes (215 adultes de la population générale, 251 étudiants et 686 personnes présentant des troubles somatiques (VIH, Sclérose en Plaques, douleurs chroniques, leucémie) et 24 personnes bipolaires hospitalisées pour dépression.

Résultats: la fiabilité interne de l'échelle totale est bonne, avec un alpha de Cronbach de .91. La structure en cinq facteurs est très proche de celle de l'échelle anglaise.

Conclusion: La version française de l’EPS possède une bonne validité. Les corrélations avec d'autres outils proches sur le plan conceptuel (e.g. TAS-20, CERQ, STAXI) sont conformes aux attendus. Les scores à l'EPS permettent de distinguer les populations tout-venant et clinique.

Mots clés : traitement des émotions; Echelle des processus émotionnels; adaptation française; population tout-venant; population clinique

\section{Abstract}

Aim: The Emotional Processing Scale (EPS) is a self-report questionnaire consisting of 25 items designed to identify emotional processing styles and impairments. The aim was to develop a French version of the scale and to test its preliminary validity and reliability in French community and clinical samples.

Method : After translation and back translation, a validation study was conducted with 1176 adults (215 from a community sample , 251 undergraduate psychology students, 686 people with a range of physical health conditions (HIV, multiple sclerosis, chronic pain, leukaemia) and 24 people with bipolar disorder hospitalised for depression.

Results: The internal reliability of the French EPS was good, with a Cronbach's alpha of .91. 
The five-factor structure of the original English version of the scale was closely reproduced. Conclusions: The French EPS demonstrated good reliability and validity. Correlations with other conceptually similar scales (e.g. TAS-20, CERQ, STAXI) were as predicted. EPS scores distinguished between groups (clinical samples vs. a community sample) that would be expected to differ.

Keywords: Emotions; Emotional Processing; Emotional Processing Scale; EPS; French translation; ; Validation;

\section{Introduction}

Emotional processing refers to a set of interrelated processes that include emotional perception (how we perceive events and identify their emotional value), emotional regulation (how emotions are managed) and emotion experiences (how emotions affect us) (Koole, 2009, Phillips, 2003a,b). In 1980 Rachman outlined emotional processing as a theory of how emotional disturbances are absorbed and processed to the point where they no longer affect an individual's behaviours and experiences. He noted that 'most people successfully process the overwhelming majority of disturbing events that occur in their life', but that failure to process events could lead to the return of fears, intrusive thoughts, abnormal grief reactions, nightmares etc. Psychological therapy was the context in which Rachman described his theory, offering explanations for both successful therapy and relapse. Foa and Kozak (1986) developed the concept to emphasise the centrality of behavioural exposure to emotional processing, applying it in particular to anxiety disorders.

In support of Rachman's theory, impairments in emotional processing and emotional regulation have been linked to a wide range of mental health conditions in adults, including anxiety and panic disorders (Baker, 2007a, 2013, Folk et al., 2014), post traumatic stress disorder (Kumpala, 2011, Rachman, 2001, Woodward et al.,, 2018, Weiss et al., 2013), obsessive compulsive disorders (Kang, 2012), eating disorders (Bydlowski, 2005), psychosis \& persecutory delusions (Baslet, 2008 ; Westermann \& Lincoln, 2011), deliberate self-harm (Gratz \& Tull, 2010; identity disorders and borderline personality disorder (Kaufman, 2015; Bilbo, 2010, ); attention-deficit/hyperactivity disorders (Mitchell et al., 2012) substance abuse (Dvorak et al., 2014), depression (Honkalampi, 2000, Joormann, 2010), eating disorders (Lavenderet al., 2014; Racine \& Wildes, 2013; Smith et al., 2019), psychopathic personality characteristics (Donahue et al., 2014), internalizing and externalizing disorders 
(Berke et al., 2018; Carver \& Johnson, 2018; Naragon-Gainey et al, 2018; Hofmann et al., 2012), in psoriasis (Almeida et al., 2017), pain (Elbèze \& Gay 2012; Esteves et al., 2013) and medical conditions (Blumenau 2012),

Although Rachman's theory focuses on the outcomes of successful or unsuccessful processing, it does not specify the psychological mechanisms that might be involved in the processing itself. Baker developed an expanded emotional processing model which specified psychological mechanisms by which the emotional processing of stressful events might be facilitated or impeded, described in 2007, 2010, and 2015. The model is an integrative one, drawing on emotion theory (e.g. Bucci 1997, Epstein 1998), cognitive theory (e.g. Kelly 1963, Ortony et al.,1988), experiential theory and therapy (e.g. Gendlin 1996, Rogers, 1959) and major therapeutic orientations such as behaviour therapy (e.g. Marks 1978), cognitive therapy (e.g. Beck et al., 1985), psychotherapy (e.g. Freud, 1909) as well as psychosomatic (e.g. Seyle 1956; Traue \& Pennebaker, 1993) and neuropsychological research (e.g. Damasio, 1999, LeDoux, 1998).

The model is organised into three stages; the input of a stressful event (involving perception, cognitive appraisal, memory and schemas) an experiential stage (awareness, experience, labelling and linking of emotional states) and an expression stage (verbal, behavioural, physiological).

Emotional processing overlaps with several other emotion concepts including emotional awareness (Lane \& Nadel, 2002), alexithymia (Taylor \& Bagby, 1986), emotional focusing (Gendlin, 1996), emotional intelligence (Salovey \& Mayer, 1990), and emotion regulation (Gross, 1988), discussed more fully in Baker et al. 2015. Baker's model is somewhat broader than these approaches, focusing on the complex interplay of many different psychological mechanisms working together as a change process. It relates to psychological therapy in relation to the process of moving from unresolved to resolved emotional states, and to psychopathology, with regard to the emotional mechanisms by which psychological problems develop and may help to understand the high rates of comorbidity across various diagnoses On the basis of this multifaceted model Baker and colleagues developed an Emotional Processing Scale (EPS) (Baker et al 2007, 2010, 2015).

There are many scales that have examined aspects of emotional processing over the last 
twenty years. Three categories of scales may be of particular interest: in the understanding of emotional processing, those linked to the perception of emotions : e.g. Toronto Alexithymia Scale-20 items (TAS-20) (Bagby, taylor et al., 1994), Taylor et al., 1986), Levels of Emotional Awareness Scale (LEAS) (Lane \& Nadel, 1990), State-Trait Anger Expression Inventory (STAXI) (Spielberger et al., 1999), those linked to the regulation of emotions, e.g.the Cognitive Emotion Regulation Questionnaire CERQ (Garnefski et al., 2001), the Difficulties in Emotion Regulation Scale (DERS) (Gratz \& Roemer, 2004), Emotion Regulation Questionnaire (ERQ) (Gross \& John, 2003) ; Regulation of Emotion Systems Survey (RESS) (De France \& Hollenstein, 2017), the Emotional Expressiveness Questionnaire (EEQ) (Kring \& Emmons, 1990), Emotional Expressivity Scale (EES) (Kring, 1994), Berkeley Expressivity Questionnaire (BEQ) (Gross, 1995) and those linked to the experience of emotion : e.g. Depression, Anxiety and Stress Scale (DASS 21) (Norton, 2007), Hospital Anxiety and Depression Scale (HADS) (Zigmond et Snaith, 1983); The PTSD Checklist (PCL) (Blanchard, 1996). However, few scales draw together the multiple dimensions of emotional processing.

The EPS has been developed for several different purposes: 1) to identify and measure emotional processing styles in the general population as well as those with psychological or physical disorders; 2) to provide a means of categorising emotional processing styles that could be applied in therapeutic or research contexts: 3) to predict treatment response; 4) to determine whether impairments in emotional processing contribute to the development of physical, psychosomatic, and psychological disorders, and 5) to provide a means of measuring changes in emotional processing following therapeutic interventions.

In the original validation work Baker et al. (2007, 2010) reported the EPS to be reliable and valid with satisfactory internal consistency and possessing a five-factor structure as follows:

i. 'Suppression', which relates to an excessive control of emotions, ii. 'Signs of unprocessed emotions' which consists of intrusive and persistent emotional experiences; iii. 'Controllability of emotions' which relates to the ability to control one's expression of emotions; iv. 'Avoidance' which involves the avoidance of negative emotions and finally v. 'Emotional experience' which relates to emotional detachment and poor emotional insight.

The EPS has been used in psychological disorders (e.g. trauma, Horsham \& Chung 2013, 
anxiety and depression (Gay, 2010, 2017, Johansson et al 2012, Kealy, Ogrodniczuk \& Howell-Jones 2011), psychogenic conditions (Novakova et al., 2015), to assess therapy ( Baker et al., 2012), cultural comparisons (Kwasniewska et al.,) and in the general population (Wilkins, Baker, Bick \& Thomas 2009).

The aim of this article is to present the French adaptation of the EPS-25.

\section{Methods}

\section{Translation and back-translation}

In 2010 Gay \& colleagues translated and back-translated the EPS into French and between 2010 and 2016 conducted the validation study. One set of translation and back-translation of the EPS was conducted. The translator was a French researcher in psychology and the back translator was a bilingual French-English professional translator, with a $\mathrm{PhD}$ in psychology. The draft French version of the EPS was administered face-to-face to 6 people with MS. After completing the draft French version of the EPS they were asked a series of probe questions such as “what do you mean by that response?" This enabled any issues with wording or interpretation to be identified and resolved. Following discussion with the English authors of the scale the final version of the scale was produced.

\section{Participants}

As with the original English validation study, and in line with best practice recommendations (Godfred et al., 2018), the validation sample was heterogeneous and included clinical patient samples in addition to a community sample. Watson \& Clark (1995) noted that, if a scale is to be used in clinical settings, it is important to obtain data from patient samples early on rather than relying solely on student and general population samples that may not reflect the range of the target population.

The validation study involved 1176 adults: 215 from a community sample of city hall employees, 251 undergraduate students, 653 people with physical conditions (134 HIV, 172 chronic pain, 347 multiple sclerosis, 33 leukemia) and 24 hospitalised with bipolar depression. The mean age was 40 years $(S D=15.7)$ and ranged from 16 to 82 years. Just over two-thirds were female, approximately half of the sample were married or cohabiting and three-quarters had obtained the French Baccalauréat (an academic qualification taken at the end of high school) or higher. 


\section{Recruitment}

The community sample comprised Nanterre City Hall employees. Questionnaireswere returned anonymously to a collection box at the reception desk. Respondents were asked whether they had a long-term physical or mental health condition or had "suffered intense stress or a traumatic event in the past month”.. Questionnaires from respondents who responded 'yes' to either or both of these questions were excluded from the analysis.

The students were first year psychology undergraduate students from Paris-Nanterre University who gained course credit for their participation.

Individuals with physical health conditions were recruited from outpatient clinics at French hospitals: people with multiple sclerosis were recruited from the neurological outpatient departments of two French hospitals (Centre Hospitalier Intercommunal de Poissy-St Germain and Lyon CHU; CPP Ile de France XI -St Germain n²012_03_02). People with HIV were recruited from the Tropical and Infectious Diseases outpatients Department at the Parisian Pitié-Salpêtrière Hospital (CPP Ile de France XI -St Germain n²011_10_17), people with chronic pain were recruited from the Parisian Pain Treatment outpatients Department from the Pitié-Salpêtrière Hospital, the Hôtel-Dieu Hospital and the Argenteuil Hospital (CPP Hopital Robert Ballanger $n^{\circ}$ : 2014_11_04). People with leukaemia were recruited from the Haematology outpatient department at the Parisian Saint-Louis Hospital (CPP Ile de France XI -St Germain n²013_09_20) and people with bipolar disorder were inpatients recruited from the Psychiatry Department at the Pitié-Salpêtrière Hospital (CPP Ile de France XI -St Germain n²014_02_7)

Ethical approval for the study was obtained from the research ethics committee (Commission Nationale Informatique et Liberté (CNIL), Paris Nanterre University).

Patients were asked to take part in the study by a clinician before their consultation or, in the case of inpatients, during their admission.. The research was described as an investigation into how people deal with their illness on a daily basis. If they agreed to take part in the study, a researcher, obtained their written consent and demographic and medical information. Participants completed the battery of self-reported outcome measures before their consultation/during their admission.. Recruitment took place between 2011 and 2015. 


\section{Outcome measures}

To assess convergent validity, we used the following scales that have been translated and validated for French populations: the Toronto Alexithymia Scale-20 (TAS-20); the State Trait Anger Expression Inventory (STAXI), the Cognitive Emotion Regulation Questionnaire (CERQ), the Emotion Regulation Questionnaire (ERQ) and the Hospital Anxiety and Depression Scale (HADS).

The TAS-20, ERQ, CERQ, STAXI capture different aspects of emotion recognition and regulation. The TAS-20 (alexithymia scale) is conceptually closest to Factor 5 (Impoverished emotional experience) of the EPS-25, the STAXI (anger inventory) to Factor 3 (Signs of unprocessed emotions) and Factor 4 (Avoidance) of the EPS. The ERQ assesses emotional suppression similar to Factor 1 (Suppression) of the EPS. The CERQ assesses intrusive and persistent emotional experiences and is closest to Factor 2 (Unregulated emotion) of the EPS. The HADS is a symptom scale that assesses levels of anxiety and depression.

\section{Toronto Alexithymia Scale-20 items (TAS-20)}

The Toronto Alexithymia Scale (TAS-20, Bagby, Taylor \& Parker, 1994, French adaptation: Loas \& al., 1997) is a 20-item self-report scale that measures three factors: 'Difficulty identifying feelings', 'Difficulty describing feelings to others' and 'External concrete thinking'. Each item is rated on a 5-point Likert-type scale ranging from 1 (strongly disagree) to 5 (strongly agree) and 5 items are reverse scored. Total scores can range from 20 to 100 . We used the North American cut-off (a score of 60 or more, Bagby \& al, 1994) for determining the presence of alexithymia in order to facilitate comparison with other studies, most of which use this cut-off.

\section{Hospital Anxiety and Depression Scale (HADS)}

The Hospital Anxiety and Depression Scale (HADS, Zigmond \& Snaith, 1983; French adaptation: Lépine et al., 1985) is a 14-item scale that uses a 4-point Likert-type response format to assess an individual's self-reported anxiety and depression. Each subscale (anxiety and depression) comprises 7 items. Scores for the depression and anxiety subscales can range from $0-21$, with a score $>10$ indicating probable depression or anxiety. The French adaptation of the HADS confirmed Zigmond and Snaith's original two factor structure and has been shown to possess good psychometric properties. Internal reliability was 0.79 for the 
anxiety subscale and 0.82 for the depression subscale. The correlation between the two subscales was significant but moderate $(r=.47)$.

\section{Cognitive Emotion Regulation Questionnaire (CERQ)}

The Cognitive Emotion Regulation Questionnaire (CERQ, Garnefski, Kraaij \& Spinhoven, P., 2001; French adaptation: Jermann, Van der Linden, d'Acremont \& Zermatten, 2006) is a 36item self-report multi-dimensional questionnaire designed to identify the cognitive emotion regulation strategies used by an individual following negative events or situations. It consists of nine subscales: self-blame, blaming others, acceptance, rumination, positive re-appraisal, positive refocusing, focusing on planning, putting into perspective, catastrophising. It uses a 5-point Likert-type response format, from 1 to 5 . Each subscale comprises 4 items and the subscale scores can range from 4 to 20. Higher scores indicate greater use of the respective emotion regulation strategies.

\section{Emotion Regulation Questionnaire (ERQ)}

The Emotion Regulation Questionnaire (ERQ, Gross \& John, 2003, French adaptation: Christophe, Antoine, Leroy \& Delelis, 2009) is a 10-item self-report questionnaire designed to assess an individual's tendency to use each of two emotion regulation strategies: (i) cognitive reappraisal (six items)) and (ii) expressive suppression (four items). Items in the scale are rated via a 7-point Likert-type response scale ranging from 1 (strongly agree) to 7 (strongly disagree). Total scores can range from 10 to 70 . Higher scores indicate greater use of the respective emotion regulation strategies.

\section{State-Trait Anger Expression Inventory (STAXI)}

The State-Trait Anger Expression Inventory (STAXI-2, Spielberger, 1999; French adaptation: Borteyrou et al., 2008) is a 57-item measure of the intensity of anger and the frequency with which anger is experienced, controlled and expressed. It comprises the state and trait anger scales (Spielberger, Jacobs, Russell \& Crane, 1983) and the anger expression scale (AX; Spielberger et al., 1985). It uses a 4-point Likert-type response scale ranging from 1 to 4 . The higher the score the more the respective dimension applies. . The State Anger Scale (SAS) incorporates three subscales, namely: feeling angry, feeling like expressing anger verbally, and feeling like expressing anger physically. The scale comprises 15 items (items 1 to 15). The Trait Anger Scale (TAS) comprises 10 items (from 16 to 25) and consists of two 
subscales: Angry Temperament and Angry Reaction. The AX scale comprises 32 items (items 26 to 57). It considers the direction of both anger expression and anger control, resulting in four AX subscales: anger expression/out (verbal and physical, aggressive behavior directed toward other people or objects), and anger expression/in (holding in anger), anger control/out (attempts to monitor and inhibit the outward expression of anger) and anger control/in (active attempts to calm down). An Index AX is obtained by subtracting anger control scores from control expression scores and can range from 0 to 96.

\section{Predictions}

We expected that the EPS subscales would correlate most strongly with theoretically-related scales. The English validation of the EPS found that it correlated highly with Factors 1 and 2 of the TAS-20 but not Factor 3 and so we expected a similar pattern in the French data. We expected that conceptually similar subscales would be significantly correlated; for example, that the 'Suppression' subscale of the EPS would correlate highly with the 'Expressive suppression' subscale of the ERQ and that the 'Unregulated emotions' subscale would correlate highly with those subscales of the STAXI related to anger.

In the English validation of the EPS (Baker 2007) only modest correlations were obtained between most EPS subscales and a measure of anxiety and depression suggesting that the EPS is not merely a proxy measure of psychiatric disturbance. We expected this pattern to be replicated. We expected that patients with physical health conditions (HIV, multiple sclerosis, chronic pain, leukemia) would tend to score more highly on the EPS (i.e. exhibit greater emotional processing impairments) than the community sample.

\section{Procedure}

All participants completed the EPS and the TAS-20. The community subsample City Hall employees $(\mathrm{n}=72)$ also completed the CERQ, ERQ, STAXI and HADS.

\section{Analysis}

Data analysis was undertaken using SPSS Version 21. Internal reliability was assessed using Cronbach's alpha. In keeping with the original factor analysis undertaken by Baker et al. (2010), a Maximum Likelihood Factor Analysis with Promax rotation was undertaken with 
the number of factors to extract pre-specified as five. Items with loadings $\geq .30$ were retained.

Convergent validity of the EPS was assessed by calculating correlation coefficients (Pearson's Product-Moment) between the respective EPS subscales and other measures of theoreticallyrelated constructs.

One-way analysis of variance followed by Dunnett's post-hoc multiple comparison test was used to test whether there were significant differences in EPS scores between the community sample and those with physical or mental health conditions.

Eighteen respondents had missing data and were excluded from the analysis.

\section{Results}

\section{Internal reliability}

The coefficient $\alpha$ value for the EPS was .91. Internal consistency was high $(\alpha=.86)$ for the Suppression factor and moderate for the other four factors (between .67 and .80). Table 1 presents the internal consistency findings from Baker et al. (2010) alongside those obtained in the current study.

Insert Table 1 about here

\section{Maximum Likelihood Factor Analysis}

Table 2 presents the factor loadings obtained by Baker et al. (2010) alongside those obtained for the French adaptation of the scale. All items loaded on one of the five pre-specified factors at .30 or higher. Three items had cross-loadings (items 17, 23 \& 10). Cross-loadings were not unexpected give that there is likely to be some degree of conceptual overlap between the subscales.

The factor structure and pattern of loadings closely resembled that of Baker et al., with a few exceptions. While items 10 and 23 loaded $\geq .30$ on the same respective factors as in the English version of the scale (item 10 on Factor 5 (.30) and item 23 on Factor $3(.30)$ ) they also loaded on a different factor more highly (item 10 on Factor 3 (.35) and item 23 on Factor 2 (.58). Item 17 had a pattern of cross-loadings similar to that found in the English version of 
the scale. It loaded most strongly on Factor 2 (.52) but, as in the English version of the scale, had another (weaker) loading on Factor 3 (.35). Finally, as in the English version of the scale, item 9 loaded on Factor 2 rather than Factor 3. . We note that in the English version item 9 possessed the lowest loading (.30) of all 25 items.

Insert Table 2 about here

\section{Correlations between the EPS subscales}

Pearson Product-Moment Correlation Coefficients $\left(r_{p}\right)$ between the five subscale scores (Suppression, Unregulated emotion, Impoverished emotional experience, Signs of unprocessed emotions, Avoidance) and the EPS total score were .76, .81, .76, .79, and .81, respectively, ( $p s<.001)$. The corresponding correlations in the English sample were $.76, .73, .83, .81$ and .73 . The mean inter-item correlation for the French sample was .29. Correlations between the five subscales ranged from 0.41 to 0.64 , compared to .34 and .59 in the English sample.

\section{Between group differences}

There were significant between-group differences on EPS total scores $\mathrm{F}=8.57$, d.f. $=6, \mathrm{p}<$ 0.001. Dunnett's post-hoc tests indicated that all clinical groups (chronic pain, MS, HIV, leukemia, bipolar disorders) had significantly higher EPS total scores than the community sample (see Table 4).

Insert Table 3 about here

\section{Convergent validity}

In all, as 180 correlations were calculated, by chance one would expect to find nine significant correlations at $\mathrm{p}<.05$ and two at $\mathrm{p}<.01$. There were 51 correlations of at least $\mathrm{p}<.01$ suggesting many close relationships between the EPS and related scales.

Table 3 presents the correlations between the EPS and the other scales that were administered. 
In line with the findings of Baker et al. (2007), the EPS total score was moderately positively correlated with the TAS-20 total score. There was no significant correlation with Factor 3 of the TAS-20 (Externalised way of thinking) which is considered the core of alexithymia.

The 'Suppression' subscale of the EPS had a strong positive correlation with the 'Suppression of emotional expression' subscale of the ERQ (.62) and with the 'Suppression of anger expression' subscale of the STAXI (.57) and was moderately negatively correlated with the 'Cognitive Reappraisal' subscale of the CERQ (-.44).

The 'Unprocessed emotions' subscale of the EPS was moderately positively correlated with the Self-blame (.49), Rumination (.33) and Catastrophising subscales (.32) of the CERQ.

The 'Unregulated emotions' subscale of the EPS had a moderate positive correlation with the STAXI's Anger-trait dimension (.49) and its two subscales: Angry temperament (.41) and Angry reaction (.40). It was also positively correlated with items assessing Externalised expression of anger (.46), which consists of aggressive behaviour directed toward other persons or objects. It correlated more strongly with the Anger-trait subscale (.49) than with the Anger-state subscale (.33).

The 'Avoidance' subscale of the EPS was moderately negatively correlated with the 'Refocus on planning' (-.31) and 'Positive reappraisal' (-.31) subscales of the CERQ, and had a moderate positive correlation with the 'Expressive suppression' (.36) item of the ERQ and with the 'Suppression of anger expression' subscales of the STAXI (.52).

The 'Impoverished emotional experience' subscale had a strong positive correlation with the 'Difficulty in identifying feelings' subscale of the TAS-20 (.60) and a moderate positive correlation with several dimensions of anger-state assessed by the STAXI: 'Feeling angry' (.44) and 'Feeling like expressing anger' (.50).

The TAS-20 total score and the 'Difficulty in describing feelings' and 'Difficulty in identifying feelings' subscales correlated positively with all subscales of the EPS and more specifically with Factor 3. The 'Externalised way of thinking' subscale of the TAS-20 did not correlate significantly with any of the EPS subscales. 
The 'Self-blame' subscale of the CERQ correlated positively with each subscale of the EPS. The 'Suppression of expression of anger' subscale of the STAXI correlated positively with all EPS subscales with the exception of 'Unregulated emotions'.

There were moderate positive correlations between each subscale of the EPS and the Anxiety and Depression subscales of the HADS; similar to those reported in the original English validation of the EPS (see Table 4).

Insert Table 4 about here

\section{Discussion}

The internal consistency of the French version of the EPS was high and Cronbach's alphas were similar to those obtained for the English version of the EPS (Baker et al. 2010).

The correlations obtained between the EPS subscales and the EPS total score were high and moderate between the five respective subscales. The inter-item correlations were satisfactory. Again these findings were similar to those obtained for the validation of the English version of the scale.

The factor analysis resulted in a very similar factor structure to that obtained for the English version, with comparable factor loadings. There were 2/25 items that possessed a crossloading $>0.3$ on another factor (see Table 2). The EPS total scores discriminated between groups that might be expected to differ in emotional processing styles (e.g. clinical vs. community samples) and tends to confirm that students' samples are not representative of the general population.

In terms of convergent validity, the pattern of correlations with other scales was largely as one would expect, with the EPS correlating most strongly with other scales/subscales measuring similar dimensions. For example, there were high positive correlations between the Suppression subscale of the EPS and the 'Suppression of emotional expression' subscale of the ERQ. As with the English version of the scale, there were moderate correlations with Factors 1 and 2 of the TAS-20. The pattern of correlations provides useful information about 
the meaning of the EPS subscales. Some of the most consistent patterns were the relationships between all subscales of the EPS and anxiety and depression symptoms and between all subscales of the EPS and State anger and Anger expression of the STAXI. It is interesting that the EPS, designed to measure emotions in general, correlated moderately with three different aspects of emotions; namely, anger, anxiety, and depression.

A mixed pattern of correlations was observed between the EPS and the TAS-20 scale. The 'Externally oriented' subscale of the TAS was not significantly correlated with any of the EPS subscales, nor the total score. The strongest correlations were with the 'Identifying feelings' subscale which is an important aspect of healthy emotional processing.

There were significant correlations between the 'Self-blame' subscale of the CERQ and all EPS subscales and between the 'Positive appraisal' subscale of the CERQ (positive correlation) and the 'Suppression" and “Avoidance' subscales of the EPS (negative correlation). There were also significant positive correlations between the 'Catastrophising' subscale of the CERQ and the 'Signs of Unprocessed emotions' and 'Unregulated emotion' EPS subscales. This pattern of correlations suggests that these negative cognitive styles are associated with poor emotional processing.

In conclusion, this first validation of a French version of the EPS was promising. The French version has good internal reliability, a robust factor structure similar to that obtained in the original English version, and was able to distinguish between clinical samples and a community sample The correlation matrix revealed a pattern of consistent associations between the EPS and other related instruments that provide further insights into the meaning of the emotional processing subscales.

This study complements others that have demonstrated that the EPS can be translated and used cross-culturally with acceptable psychometric properties (Baker et al., 2015). A potential limitation of this study is the relatively small sample used to assess convergent validity and the small sample sizes for leukemia and bipolar disorders.

The current study extends the work of the original validation study by comparing the EPS with a greater range of other psychometrically valid scales, particularly scales measuring emotion regulation such as the CERQ and the ERQ. The EPS assesses a broader range of 
emotional processes than other available emotion scales. and has relevance for both clinical and research settings. In clinical contexts it offers a transdiagnostic assessment framework that can assist therapists to incorporate emotional components into their treatments. It offers a way of measuring change for clinical and/or research purposes as well as a means to explore the mechanisms underlying emotional processing more comprehensively. Further validation work is planned to explore convergent validity in other samples, obtain test-retest reliability data and use confirmatory factor analysis.

\section{Conflict of interest}

There are no conflicts of interest. 
References

Almeida, V., Taveira, S., Teixeira, M., Almeida, I., Rocha, J., \& Teixeira, A. (2017). Emotion regulation in patients with psoriasis: Correlates of disability, clinical dimensions, and psychopathology symptoms. International Journal of Behavioral Medicine, 24(4), 563-570 doi: $\underline{10.1007 / s 12529-016-9617-0}$

Bagby, R., M., Parker, J.D.A. \& Taylor, G.J. (1994). "The twenty-item Toronto Alexithymia scale-I. Item selection and cross-validation of the factor structure". Journal of Psychosomatic Research. 38 (1): 23-32. doi:10.1016/0022-3999(94)90005-1. ISSN 00223999.

Bagby, R.M., Taylor, G.J. \& Parker, J.D.A. (1994). The 20-item Toronto Alexithymia Scale: II Convergent, discriminant, and concurrent validity. Journal of Psychosomatic Research, 38:33 - 40. DOI: http://dx.doi.org/10.1016/S0022-3999(02)00601-3

Baker, R. (2007). Emotional Processing: healing through feeling. Oxford : Lion Publishing

Baker, R., Thomas, P., Thomas, S., Santonastaso, M., \& Corrigan, E. (2015). Emotional Processing Scale. Oxford, UK: Hogrefe.

Baker, R.; Gale, L.; Abbey, G., Thomas, S. (2013). Emotional processing therapy for post traumatic stress disorder. Counselling Psychology Quarterly, 26(3-4), 362-385. http://dx.doi.org/10.1080/09515070.2013.816840

Baker, R., Owens, M., Thomas, S., Whittlesea, A., Abbey, G., Gower, P., Tosunlar, L., Corrigan, E. and Thomas, P.W. (2012) Does CBT facilitate emotional processing? Behavioural and Cognitive Psychotherapy, 40(1):19-37. doi: 10.1017/S1352465810000895.

Baker, R., Thomas, S., Thomas, P.W., Gower, P, Santonastaso, M. \& Whittlesea, A. (2010). The Emotional Processing Scale: scale refinement and abridgement (EPS-25) Journal of Psychosomatic Research, 68, 83-88 doi: 10.1016/j

Baker, R., Thomas, S., Thomas, P.W. \& Owens, M. (2007a). Development of an Emotional Processing Scale. Journal of Psychosomatic Research, 62,167-178. DOI: 10.1016/j.jpsychores.2006.09.005

Baker, R., Holloway, J., Thomas, P.W., Thomas, S. \& Owens, M (2004). Emotional Processing and Panic. Behaviour Research and Therapy, 42, 1271-1287 DOI: 10.1016/j.brat.2003.09.002

Baslet, G., Termini, L., Herbener, E. (2009). Deficits in emotional awareness in schizophrenia and their relationship with other measures of functioning. Journal of Nervous and Mental Disease, 197(9), 655-660. doi: 10.1097/NMD.0b013e3181b3b20f 
Beck, A. T., Emery, G., \& Greenberg, R. L. (1985). Anxiety disorders and phobias: A cognitive perspective. New York, NY: Basic Books

Berke, D.S., Reidy, D., \& Zeichner, A. (2018) Masculinity, emotion regulation, and psychopathology: A critical review and integrated model. Clinical Psychology Review, 66, 106-116. doi: 10.1016/j.cpr.2018.01.004

Beblo, T.1., Pastuszak, A., Griepenstroh, J., Fernando, S., Driessen, M., Schütz, A., Rentzsch, K. \& Schlosser, N. (2010). Self-reported emotional dysregulation but no impairment of emotional intelligence in borderline personality disorder: an explorative study. J Nerv Ment Dis. 198(5):385-8. doi: 10.1097/NMD.0b013e3181da4b4f.

Blanchard, E.B., Jones-Alexander,J., Buckley, T.C., Forneris, C.A. (1996) Psychometric properties of the PTSD Checklist (PCL). Behaviour Research and Therapy, 34, 669-673. doi:10.1016/0005-7967(96)00033-2

Blumenau, J. (2012). Factors affecting personality change following stroke (Unpublished thesis). University of Witwaterrand, Johannesburg, South Africa.

Borteyrou, Bruchon-Schweitzer M.L. \& Spielberger C.D. (2008). The French adaptation of the STAXI-2, C.D. Spielberger's State-trait anger expression inventory. L'Encéphale. 34, 249—255. DOI: 10.1016/j.encep.2007.06.001

Bucci, W. (1997a). Psychoanalysis and cognitive science: A multiple code theory. New York, NY: The Guilford Press

Bydlowski, S.1., Corcos, M., Jeammet, P., Paterniti, S., Berthoz, S., Laurier, C., Chambry, J. \& Consoli, S.M. (2005). Emotion-processing deficits in eating disorders. Int J Eat Disord. 37(4):321-9. DOI: 10.1002/eat.20132

Carver, C.S., \& Johnson, S.L. (2018). Impulsive reactivity to emotion and vulnerability to psychopathology, American Psychologist, 73(9), 1067-1078.

Christophe, V., Antoine, P., Leroy, T. \& Delelis, G. (2009). Assessment of two emotional regulation processes: Expressive suppression and cognitive reevaluation, Revue Européenne de Psychologie Appliquée - European Review of Applied Psychology, 59 , 59-67. http://dx.doi.org/10.1016/j.erap.2008.07.001

Clarke LA, Watson D. (1995) Constructing validity: basic issues in objective scale development. Pyschol Assess. 7:309-19. doi: 10.1037/1040-3590.7.3.309

Damasio, A. (1999). The feeling of what happens: Body, emotion and the making of consciousness. San Diego, CA: Harcourt.

De France, K., \& Hollenstein, T (2017) Assessing emotion regulation repertoires: The Regulation of Emotion Systems Survey. Personality and Individual Differences. 119, 1: 204215. https://doi.org/10.1016/j.paid.2017.07.018 
Donahue, J.J., McClure, K.S., \& Moon, S.M. (2014). The relationship between emotion regulation difficulties and psychopathic personality characteristics.

Personality Disorders: Theory, Research, and Treatment, 5(2), 186-194. Doi:

10.1037/per0000025

Dvorak, R. D., Sargent, E. M., Kilwein, T. M., Stevenson, B. L., Kuvaas, N. J., \& Williams, T. J. (2014). Alcohol use and alcohol-related consequences: associations with emotion regulation difficulties. The American Journal of Drug and Alcohol Abuse, 40, 125130.doi:10.3109/00952990.2013.877920

Elbèze Rimasson, D. \& Gay, M.C., (2012) Le fonctionnement émotionnel lors de la douleur chronique, Annales Médico Psychologiques 170(3), 163-168. https://doi.org/10.1016/ j.amp.2011.03.015

Epstein, S. (1998). Emotion and psychopathology from the perspective of cognitiveexperiential self-theory. In W. F. Flack \& J. D. Laird (Eds.), Emotions in psychopathology. New York, NY: Oxford University Press.

Esteves, J. E., Wheatley, L., Mayall, C. \& Abbey, H. (2013). Emotional processing and its relationship to chronic low back pain: Results from a case-control study. Manual therapy, 18, 541-546. DOI: 10.1016/j.math.2013.05.008

Foa, E. B., \& Kozak, M. J. (1986). Emotional processing of fear: Exposure to corrective information. Psychological Bulletin, 99, 20-35. http://dx.doi.org/10.1037/0022-006X.51.2.28

Folk, J. B., Zeman, J. L., Poon, J. A., \& Dallaire, D. H. (2014). A longitudinal examination of emotion regulation: pathways to anxiety and depressive symptoms in urban minority youth. Child and Adolescent Mental Health. doi:10.1111/camh.12058.

Fossati, A., Feeney, J., Maffei, C., \& Borroni, S. (2014). Thinking about feelings: affective state mentalization, attachment styles, and borderline personality disorder features among Italian nonclinical adolescents. Psychoanalytic Psychology, 31, 41-67. doi:10.1037/a0033960

Freud, S. (1909). Selected papers on hysteria and other psychoneuroses. New York, NY: The Journal of Nervous and Mental Disease.

Garnefski, N., Kraaij, V., \& Spinhoven, P. (2001). Negative life events, cognitive emotion regulation and emotional problems. Personality and Individuals Differences, 30, 1311-1327. https://doi.org/10.1016/S0191-8869(00)00113-6

Gay, M.C., Vrignaud, P., Garitte, C. \& Meunier C. (2010) Predictors of depression in Multiple Sclerosis, Acta Neurologica Scandinavica, 121(3), 161-170. https://doi.org/10.1111/j.1600-0404.2009.01232.x

Gay, MC, Bungener C., Thomas S., Vrignaud, P., Thomas, P., Heinzlef, O. \& Montreuil, M. (2017): Anxiety, emotional processing and depression in patients with Multiple Sclerosis, Neuro BMC Neurology 17(1) · DOI: 10.1186/s12883-017-0803-8

Gendlin, E. T. (1996). Focusing-oriented psychotherapy: A manual of the experiential method. New York, NY: The Guildford Press. 
Godfred O. Boateng,1., Torsten B. Neilands, E.A., Frongillo, H.R. Melgar-Quiñonez \& Young S.L. (2018) Best Practices for Developing and Validating Scales for Health, Social, and Behavioral Research: A Primer. Frontiers in Public Health. 11 doi: 10.3389/fpubh.2018.00149

Gratz, K.L. \& Roemer, L. (2004). Multidimensional Assessment of Emotion Regulation and Dysregulation: Development, Factor Structure, and Initial Validation of the Difficulties in Emotion Regulation Scale. Journal of Psychopathology and Behavioral Assessment. 26, 1, 41-54. http://dx.doi.org/10.1007/s10862-008-9102-4.

Gratz, K. L., \& Tull, M. T. (2010). The relationship between emotion dysregulation and deliberate self-harm among inpatients with substance use disorders. Cognitive Therapy and Research, 34, 544-553. doi:10.1007/s10608-009-9268-4

Gross, J. J. (Ed.). (2009). Handbook of emotion regulation. New York, NY: The Guildford Press.

Gross, J.J., \& John, O.P. (2003). Individual differences in two emotion regulation processes: Implications for affect, relationships, and well-being. Journal of Personality and Social Psychology, 85, 348-362. DOI: 10.1037/0022-3514.85.2.348

Gross, J.J. (2000). The Berkeley Expressivity Questionnaire. In J. Maltby, C.A. Lewis, \& A.P. Hill (Eds.), Commissioned reviews on 300 psychological tests (pp. 465-467). Lampeter, Wales: Edwin Mellen Press.

Henry, J.D., Crawford, J.R., Bedford, A., Crombie, C. \& Taylor, E.P. (2002).The Personal Disturbance Scale (sAD): normative data and latent structure in a large non-clinical sample. Personality and Individual Differences. 33:1343- 60. https://doi.org/10.1016/S0191$\underline{8869(96) 00242-5}$

Hofmann, S. G., Sawyer, A. T., Fang, A., \& Asnaani, A. (2012). Emotion dysregulation model of mood and anxiety disorders. Depression and Anxiety, 29, 409-416. doi:10.1002/da.21888.

Honkalampi, K.1., Hintikka, J., Tanskanen, A., Lehtonen, J. \& Viinamäki, H. (2000). Depression is strongly associated with alexithymia in the general population. $J$ Psychosom Res. 48(1):99-104. DOI: 10.1159/000012412

Horsham, S., \& Chung, M. C. (2013). Investigation of the relationship between trauma and pain catastrophising: The roles of emotional processing and altered self-capacity. Psychiatry Research. 208, 274-284. http://dx.doi.org/10.1016/j.psychres.2012.11.031

Jermann, F., Van der Linden, M., d'Acremont, M., \& Zermatten, A. (2006). Cognitive Emotion Regulation Questionnaire (CERQ): Confirmatory Factor Analysis and Psychometric Properties of the French Translation. European Journal of Psychological Assessment, 22, 126131. https://doi.org/10.1016/S0191-8869(00)00113-6

Johansson, R., Hesser, H., Ljotsson, B., Frederick, R. J., \& Andersson, G. (2012). Transdiagnostic, affect focused, psychodynamic, guided self help for anxiety and depression through the internet: study protocol for randomised controlled trial. BMJ Open, 2, 1-6. doi:10.1136/bmjopen-2012-002167. 30. 
Joormann, J. \& Gotlib, I.H. (2010). Emotion Regulation in Depression: Relation to Cognitive Inhibition. Cogn Emot. 1, 24(2): 281-298. doi: 10.1080/02699930903407948

Kang, J.I., Namkoong, K., Yoo, S.W., Jhung K., \&, Kim S.J. (2012).Abnormalities of emotional awareness and perception in patients with obsessive-compulsive disorder. $J$ Affect Disord. 28 (10), 141(2-3):286-93. doi: 10.1016/j.jad.2012.04.001.

Kaufman, E. A., Cundiff, J. M., \& Crowell, S. E. (2015). The development, factor structure, and validation of the self-concept and identity measure (SCIM): A self-report assessment of clinical identity disturbance. Journal of Psychopathology and Behavioral Assessment, 9, 122133. doi:10.1007/s10862-014-9441-2.

Kealy, D., Ogrodniczuk, J. S., \& Howell-Jones, G. (2011). Object relations and emotional processing deficits among psychiatric outpatients. The Journal of Nervous and Mental Disease, 199, 132-135. http://dx.doi.org/10.1097/NMD.0b013e3182083162

Kelly, G. A. (1963). A theory of personality. New York, NY: Norton.

Kennedy-Moore, E., \& Watson, J. C. (1999). Expressing emotion: Myths, realities and therapeutic strategies. New York, NY: The Guildford Press.

King, L. A., \& Emmons, R. A. (1990). Conflict over emotional expression: Psychological and physical correlates. Journal of Personality and Social Psychology, 58, 864-877.

Kneeland, E.T., Dovidio, J.F., Joormann, J., \& Clark, M.S. (2016). Emotion malleability beliefs, emotion regulation, and psychopathology: Integrating affective and clinical science. Clinical Psychology Review, Vol 45, pp. 81-88. doi: 10.1016/j.cpr.2016.03.008

Koole, S.L. (2009). The psychology of emotion regulation: An integrative review. Cognition and Emotion. 23(1), 4-41. https://doi.org/10.1080/02699930802619031

Kring, A. M., Smith, D. A., \& Neale, J. M. (1994). Individual differences in dispositional expressiveness: Development and validation of the Emotional Expressivity Scale. Journal of Personality and Social Psychology, 66(5), 934-949.http://dx.doi.org/10.1037/00223514.66.5.934

Kumpula, M.J., Orcutt, H.K., Bardeen, J.R., \& Varkovitzky, R.L. (2011). Peritraumatic Dissociation and Experiential Avoidance as Prospective Predictors of Posttraumatic Stress Symptoms. J Abnorm Psychol., 120(3): 617-627. doi: 10.1037/a0023927

Kwasniewska, A., Thomas, K., \& Baker, R. (2014). Are there cross-cultural differences in emotional processing and social problem-solving? Polish Psychological Bulletin, 45, 205210. DOI: $10.2478 / p p b-2014-0026$

Lane, R. D., \& Nadel, L. (Eds). (2002). Cognitive neuroscience of emotion. New York, NY: Oxford University Press.

Lavender, J. M., Wonderlich, S. A., Peterson, C. B., Crosby, R. D., Engel,S. G., Mitchell, J. E., \& ... Berg, K. C. (2014). Dimensions of emotion dysregulation in bulimia nervosa. European Eating Disorders Review, 22, 212-216. 10.1002/erv.2288. doi: 10.1002/erv.2288 
LeDoux, J. E. (1998). The emotional brain: The mysterious underpinnings of emotional life. New York, NY: Touchstone.

Lépine, J.P., Godchau, M., Brun, P., \& Lemperière, T. (1985). Evaluation de l'anxiéte et de la dépression chez des patients hospitalisés dans un service de médecine interne. Annales Médico-Psychologiques, 143, 175-189. DOI: 10.1371/journal.pone.0070975

Loas, G . Parker, J .D.A., Otmani, O., Verrier, A., \& Fremaux, D. (1997). Confirmatory factor analysis of the French translation of the 20-item Toronto Alexithymia Scale. Perceptual and Motor Skills, 83, 1018. DOI: 10.2466/pms.1997.85.3.1018

Marks, I. M. (1978). Exposure treatments: Conceptual issues. In W. S. Agras (Ed.), Behaviour modification: Principles and clinical applications (2nd ed., pp. 163-242). Boston, MA: Little, Brown \& Co.

Mayer, J. D., \& Salovey, P. (1997). What is emotional intelligence? In P. Salovey \& D. J. Sluyter (Eds.), Emotional development and emotional intelligence: Implications for educators (pp. 3-31). New York, NY: Basic Books.

Mitchell, J. T., Robertson, C. D., Anastopolous, A. D., Nelson-Gray, R. O., \& Kollins, S. H. (2012). Emotion dysregulation and emotional impulsivity among adults with attentiondeficit/hyperactivity disorder: results of a preliminary study. Journal of Psychopathology and Behavioral Assessment, 34, 510-519. doi:10.1007/s10862-012-9297-2.

Naragon-Gainey, K., McMahon, T.P., \& Park, J. (2018). The contributions of affective traits and emotion regulation to internalizing disorders: Current state of the literature and measurement challenges. American Psychologist, 73(9), 1175-1186. DOI: 10.1037/amp0000371

Norton P.J. (2007). Depression Anxiety and Stress Scales (DASS-21): psychometric analysis across four racial groups. Anxiety Stress Coping. 20(3):253-65. DOI: 10.1080/10615800701309279

Novakova, B., Howlett, S., Baker, R., \& Reuber, M. (2015). Emotion processing and psychogenic non-epileptic seizures: A cross sectional comparison of patients and healthy controls. Seizure, 29, 4-10. doi: 10.1016/j.seizure.2015.03.007

Ortony, A., Clore, G. L., \& Collins, A. (1988). The cognitive structure of emotions. Cambridge: Cambridge University Press.

Phillips, M.L., Drevets, W.C., Rauch, S.L. \& Lane, R. (2003a). Neurobiology of emotion perception I: The neural basis of normal emotion perception. Biol Psychiatry. 1;54(5):504-14. DOI:10.1016/S0006-3223(03)00168-9

Phillips, M.L., Drevets, W.C., Rauch, S.L. \& Lane, R. (2003b). Neurobiology of emotion perception II: Implications for major psychiatric disorders. Biol Psychiatry. 1;54(5):515-28. DOI:10.1016/S0006-3223(03)00171-9 
Rachman, S. (1980). Emotional processing. Behaviour Research and Therapy, 18, 51-60. http://dx.doi.org/10.1016/0005-7967(80)90069-8

Rachman, S. (2001). Emotional processing, with special reference to posttraumatic stress disorder. International Review of Psychiatry,13,164-71. https://doi.org/10.1080/ $\underline{09540260120074028 .}$.

Racine, S. E., \& Wildes, J. E. (2013). Emotion dysregulation and symptoms of anorexia nervosa: the unique roles of lack of emotional awareness and impulse control difficulties when upset. International Journal of Eating Disorders, 46, 713-720. doi:10. 1002/eat.22145.

Rogers, C. R. (1959). A theory of therapy, personality, and interpersonal relationships, as developed in the client-centered framework. In S. Koch (Ed.), Psychology: A Study of a Science (Vol. 3, 184-246). New York, NY: McGraw-Hill.

Salovey, P., \& Mayer, J. D. (1990). Emotional intelligence. Imagination, Cognition, and Personality, 9, 185-211. doi:0.2190/DUGG-P24E-52WK-6CDG

Seyle, H. (1956). The stress of life. New York, NY: McGraw-Hill.

Smith, K.E., Mason, T.B.; Anderson, N.L. \& Lavender, J.M. (2019). Unpacking cognitive emotion regulation in eating disorder psychopathology: The differential relationships between rumination, thought suppression, and eating disorder symptoms among men and women. Eating Behaviors, 32, 95-100. doi: 10.1016/j.eatbeh.2019.01.003

Spielberger C.D., Sydeman, S.J., Owen, A.E. \& Marsh, B.J. (1999). Measuring anxiety and anger with the state-trait anxiety inventory (STAI) and the state-trait anger expression inventory (STAXI). In: Maruish ME, editor. The use of psychological testing for treatment planning and outcomes assessment. 2nd ed. Mahwah, NJ: Lawrence Erlbaum Associates. p. 993-1021.

Spielberger, C.D. (1999). Manual for the state-trait anger expression inventory STAXI-2. Odessa, FL: Psychological Assessment Resources. DOI: 10.1002/ 9780470479216.corpsy0942

Spielberger, C. D. Jacobs, G., Russell, S., and Crane, R. S. (1983). Assessment of anger: The State-Trait Anger Scale. In J. N. Butcher, and C. D. Spielberger (Eds.), Advances in personality assessment (Vol. 2). Hillsdale, NJ: LEA

Taylor, G. J., Bagby, R. M., \& Parker, J. D. A. (1991). The alexithymia construct: A potential paradigm for psychosomatic medicine. Psychosomatics, 32, 153-164. DOI: http://dx.doi.org/10.1016/S0033-3182(91)72086-0

Taylor, G. J., Ryan, D. and Bagby, R.M. (1986). "Toward the development of a new selfreport alexithymia scale". Psychotherapy and Psychosomatics, 44, 191-199. http://dx.doi.org/10.1159/000287912

Traue, H. C., \& Pennebaker, J. W. (Eds.). (1993). Emotion, inhibition and health. Ashland: Hogrefe \& Huber. 
Watson, L.A., \& Clarke, D. (1995) Constructing Validity: Basic Issues in Objective Scale Psychological Development, 7, 3, 309-319.

Watson M, Greer S. (1983). Development of a questionnaire measure of emotional control. Journal of Psychosomatic Research , 27:299- 305. doi: 10.1200/JCO.2007.14.8718

Weiss, N. H., Tull, M. T., Anestis, M. D., \& Gratz, K. L. (2013). The relative and unique contributions of emotion dysregulation and impulsivity to posttraumatic stress disorder among substance dependent inpatients. Drug and Alcohol Dependence, 128, 45-51. doi:10. 1016/j.drugalcdep.2012.07.017.

Westermann, S., \& Lincoln, T.M. (2011). Emotion regulation difficulties are relevant to persecutory ideation. Psychology and Psychotherapy: Theory, Research and Practice, 1 84(3), 273-287. doi: 10.1348/147608310X523019

Wilkins C, Baker R, Bick D, Thomas P. (2009) Emotional processing in childbirth: a predictor of postnatal depression? British Journal of Midwifery, 17,154-9. doi.org/10.12968/bjom.2009.17.3.40077

Woodward, E.C., Viana, A.G., Raines, E.M.; Hanna, A.E., \& Zvolensky, M.J. (2018). The role of anxiety sensitivity in the relationship between emotion dysregulation and internalizing psychopathology among trauma-exposed inpatient adolescents. Cognitive Therapy and Research, 42(6), 823-831. http://dx.doi.org/10.1007/s10608-018-9943-4

Zigmond, A.S. \& Snaith, R.P. (1983). The hospital anxiety and depression scale. Acta Psychiatrica Scandinavica, 67 :361-70. DOI: 10.1111/j.1600-0447.1983.tb09716.x 